\title{
BMJ open Repetition of a sisterhood survey at district level in Malawi: the challenge to achieve MDG 5
}

\author{
Jogchum Jan Beltman, ${ }^{1,2}$ Thomas van den Akker, ${ }^{1,3,4}$ Eva Lam, ${ }^{4}$ Mieke Moens, ${ }^{4}$ \\ Julie Kazima, ${ }^{4}$ Moses Massaquoi, ${ }^{4}$ Jos van Roosmalen ${ }^{2,3}$
}

To cite: Beltman JJ, van den Akker T, Lam E, et al. Repetition of a sisterhood survey at district level in Malawi: the challenge to achieve MDG 5. BMJ Open 2011;1:e000080.

doi:10.1136/

bmjopen-2011-000080

- Prepublication history for this paper is available online. To view these files please visit the journal online (http:// bmjopen.bmj.com).

Received 31 January 2011 Accepted 6 April 2011

This final article is available for use under the terms of the Creative Commons Attribution Non-Commercial 2.0 Licence; see http://bmjopen.bmj.com

\footnotetext{
${ }^{1}$ Thyolo District Hospital, Ministry of Health, Thyolo, Malawi

2Department of Obstetrics, Leiden University Medical Centre, Leiden, The Netherlands

${ }^{3}$ Department of Medical Humanities, VU University Medical Centre, EMGO Institute for Health and Care Research, Amsterdam, The Netherlands

${ }^{4}$ Médecins Sans Frontières Operational Centre Brussels, Malawi Mission, Thyolo, Malawi
}

Correspondence to J J Beltman; j.j.beltman@lumc.nl

\section{ABSTRACT}

Objective: To evaluate progress made at district level in Malawi towards reaching the 5th Millennium Development Goal, the reduction of maternal mortality. Methods: In 2006, community-based maternal mortality in Thyolo, Malawi was calculated by applying the 'sisterhood method', a survey that relies on participants responding to basic questions about maternal mortality in their families. Results were compared with a 1989 sisterhood study in the same district. Information on facility-based maternal mortality in 2005 was extracted from district hospital records.

Results: The community-based maternal mortality ratio (MMR) was calculated as 558 per 100000 live births $(95 \% \mathrm{Cl} 260$ to 820$)$. A comparison with the MMR from the 1989 survey (409 per 100000 live births) shows that maternal mortality had not declined. The hospital-based MMR was 994 per 100000 live births in 2005.

Conclusion: Maternal mortality in this district has not reduced and may actually have increased. The threat of failure to achieve Millennium Development Goal 5 increases the moral obligation to improve access to quality health care.

\section{INTRODUCTION}

Maternal mortality has been high on the global political agenda for years. The 2000 Millennium Summit proclaimed the improvement of maternal health as the fifth Millennium Development Goal (MDG 5). MDG 5 was ratified by 147 world leaders who subscribed to the target of reducing maternal mortality by $75 \%$ by 2015 compared to the level in $1990 .{ }^{1}$ For countries to meet this target an average decrease in the maternal mortality ratio (MMR) of $5.5 \%$ per year is needed. ${ }^{2}$

In order to monitor progress towards reaching MDG 5, it is essential that regions and countries produce accurate maternal mortality estimates. In reality, however, mortality statistics are of variable quality, and local

\section{ARTICLE SUMMARY}

\section{Article focus}

- A survey was carried out to evaluate progress made at district level in Malawi towards reducing maternal mortality.

\section{Key messages}

- Maternal mortality was measured using the sisterhood method and was compared with a 1989 sisterhood study in the same district.

- Maternal mortality in this district has not reduced and may even have increased.

Strengths and limitations of this study

- This is the first known study comparing two sisterhood surveys in the same district conducted several years apart and indicates that maternal mortality in Malawi did not decline substantially over the period between the two surveys.

- This study is limited by its small sample size. Also the results of recent initiatives to reduce the maternal mortality ratio will only be evident with repetition of the sisterhood method in $10-12$ years.

figures are usually not available. ${ }^{2}$ In some areas, vital registration data are obtained through civil registration systems. ${ }^{2-4}$ However, in resource-poor settings these systems are often not available or of poor quality. ${ }^{45}$

Since its introduction in the early 1990s, the sisterhood method has been applied in low-resource settings to estimate maternal mortality. ${ }^{6}$ This technique was designed to avoid high costs by overcoming the need for a large sample size. ${ }^{78}$ The sisterhood method has two forms: (1) the original indirect method by which maternal mortality is derived from respondents' answers to four basic questions, and (2) the direct method which is rather time-consuming and requires a larger sample size, by which respondents are asked to provide more detailed answers to 11 questions pertaining to maternal mortality in their families. In 1989, the indirect sisterhood 
method was applied in Thyolo District, Malawi. It revealed an MMR of 409 per 100000 live births. ${ }^{9}$

This present study describes a second indirect sisterhood survey carried out in the same district 17 years later in order to re-calculate community-based maternal mortality. In addition, we determined facility-based MMR at the local district hospital in 2005. We undertook this study in order to evaluate progress towards reaching MDG 5, which has been a national priority in Malawi. Several nationwide initiatives have been launched in the past to reduce maternal mortality, such as the national Safe Motherhood Task Force (1993) to guide programme development and its implementation, the National Strategic Plan of 1995, the Malawi Safe Motherhood Project 2003 and the Malawi National Road Map in 2005 for accelerating the reduction in maternal and newborn mortality. ${ }^{10-12}$

\section{MATERIALS AND METHODS \\ Setting}

Thyolo District is one of 12 districts in the southern region of Malawi, a low-income country in sub-Saharan Africa. It is a rural area that had approximately 570000 inhabitants in 2004, with an adult HIV prevalence of $21 \%$ and a fertility rate of 5.7 . In 2005, around half of the women in Thyolo delivered their babies at a formal health facility. ${ }^{3}$ There were 3085 deliveries in 2005 in Thyolo District Hospital, largest public health facility in the district. The proportion of Malawian women delivering in formal health facilities has not noticeably increased in recent decades. ${ }^{3}$

\section{Data collection and analysis}

In December 2006, we conducted a household survey applying the indirect sisterhood method. We made use of 30 randomly selected enumeration areas throughout the district. These enumeration areas were determined by the National Statistical Office of Malawi for the national Demographic and Health Survey and were used for logistical reasons. ${ }^{3}{ }^{13}$ Each area had a population of 300-2000 people, living in a maximum of five rural villages. Population data and maps were available to identify relevant communities. This design was similar to that of the 1989 survey that included 4124 randomly selected respondents from different areas in the district.

The interviewers were 10 nurse-midwife students who received dedicated training prior to the survey. All adult males and females aged 15 years or older were asked the following four questions: (1) how many sisters of reproductive age (born to the same mother) they had, (2) how many of these were alive at the time of the survey, (3) how many had died, and (4) how many had passed away during pregnancy, childbirth or within 6 weeks of giving birth. ${ }^{6}$ Interviewers were asked to verify that the sum of the answers provided to questions 2 and 3 equalled the outcome of question 1 .

For the calculation of the MMR two mathematical adjustments were carried out:
1. A correction made for the fact that respondents under the age of 25 are likely to have more sisters who will reach age 15 or get married in the future. Therefore, the number of respondents in the age group under the age of 25 was multiplied by the average number of sisters of those in the age group above 25 . This average was $2.29(3410 / 1491)$, that is each respondent above the age of 25 had 2.29 sisters above 15 years of age.

2. A correction made for the fact that sisters of respondents over 60 years of age may be expected to have undergone a complete lifetime risk of childbirth and sisters of younger respondents only part of this lifetime risk. Therefore the 'sister units of risk exposure', the reported number of sisters who had reached the age of 15, was multiplied by an adjustment factor as defined by Graham et al. ${ }^{6}$

Routinely collected hospital data concerning live births, stillbirths, neonatal deaths and maternal deaths in 2005 were extracted from hospital registers.

All data were analysed using Epi-Info 6.04 and SPSS 16 software packages. The significance level was set at $5 \%$.

\section{Outcomes}

The indirect sisterhood method gives an estimation of maternal mortality for the 10-12 years prior to the study, which is the median number of years since the death of deceased sisters. ${ }^{6}{ }^{14}$ Restricting the age limit of respondents would reduce this interval but increase the required sample size. ${ }^{7}$ Therefore, estimation of the community-based MMR in Thyolo District studied in 2006 relates to the period 1994-1996. The intention was to compare the outcome with the 1989 survey.

\section{Ethics}

Local authorities, community leaders and respondents were informed about the purpose of the survey, and verbal consent was requested from each individual respondent. Collected data did not include patient identifiers. The Malawi National Health Science Research Committee provides general oversight and approval for the collection and use of data for monitoring and evaluation purposes, and the Thyolo District Health Office and the Médecins Sans Frontières programme have approval from the committee to publish routine and de-identified programme outcomes such as those used in this study. Separate written approval was not considered necessary.

\section{RESULTS}

A total of 2286 respondents (1747 females and 539 males) in 1802 households were interviewed and divided into 5-year age groups (table 1).

The total lifetime risk of maternal death for a woman reaching the age of 15 was $3.2 \%(84 / 2641$, or 1 in 31$)$. The MMR was 558 per 100000 live births (95\% CI 260 to 820) (MMR is calculated as (total lifetime risk of death/ total fertility rate) $\times 100000$.) 


\begin{tabular}{|c|c|c|c|c|c|}
\hline $\begin{array}{l}\text { Age } \\
\text { group }\end{array}$ & $\begin{array}{l}\text { Number of } \\
\text { respondents }\end{array}$ & $\begin{array}{l}\text { Sisters reaching } \\
\text { age } 15\end{array}$ & $\begin{array}{l}\text { Maternal } \\
\text { deaths }\end{array}$ & $\begin{array}{l}\text { Adjustment } \\
\text { factor }\end{array}$ & $\begin{array}{l}\text { Sister units of } \\
\text { risk exposure } \\
\end{array}$ \\
\hline $15-19$ & 265 & 606 & 5 & 0.107 & 65 \\
\hline $20-24$ & 530 & 1212 & 16 & 0.206 & 249 \\
\hline $25-29$ & 393 & 737 & 16 & 0.343 & 253 \\
\hline $30-34$ & 297 & 652 & 14 & 0.503 & 328 \\
\hline $35-39$ & 208 & 559 & 10 & 0.664 & 371 \\
\hline $40-44$ & 118 & 264 & 6 & 0.802 & 212 \\
\hline $45-49$ & 94 & 213 & 4 & 0.900 & 192 \\
\hline $50-54$ & 102 & 252 & 1 & 0.958 & 241 \\
\hline $55-59$ & 72 & 180 & 7 & 0.986 & 177 \\
\hline $60+$ & 207 & 553 & 5 & 1.00 & 553 \\
\hline Total & 2286 & 3410 & 84 & & 2641 \\
\hline
\end{tabular}

In 2005, there were 3085 hospital deliveries with 2858 live births. Twenty-seven maternal deaths were recorded at the hospital in the same year, giving a facility-based MMR of 994 per 100000 live births.

The 1989 sisterhood survey in Thyolo had revealed an MMR of 409 per 100000 live births with no confidence intervals specified. ${ }^{9}$ Comparing the 1989 and 2006 MMRs, we calculated an OR of 1.4 (95\% CI 0.7 to 2.6) indicating no significant difference between the 1989 and 2006 MMRs.

\section{DISCUSSION}

Our findings show that the MMR in Thyolo District did not decrease significantly between the 1989 and 2006 surveys. This puts a gloomy light on the possibility to achieve the target set by MDG 5 for 2015 . The MMR of 558 per 100000 live births indicates that maternal health may even have worsened during the 17 years prior to this study.

This is one of the first studies to our knowledge performed at district level echoing the recent figures from Hogan et al indicating that maternal mortality in Malawi increased substantially during the final 20 years of the last century. This increase was primarily due to a rise in HIV-related mortality. ${ }^{15}$ In addition, the deepening of the human resources for health crisis, partly as a result of HIV, may have contributed. ${ }^{16}$

The national MMRs given by Hogan et al are considerably higher (743, 1662 and 1140 per 100000 live births in 1990, 2000 and 2008, respectively) than those found in these sisterhood surveys. It has been suggested that the sisterhood technique may lead to under-estimation of maternal mortality as biases causing under-reporting (for instance recollection bias) may outweigh those leading to overestimation. ${ }^{14}$ Since our study assessed maternal mortality for the years 1994-1996, it is possible that -in line with the trend described by Hogan et althe MMR increased further after 1996.

The MMR of 558 per 100000 live births is similar to the national MMR in the 2010 intersectional trend report that indicates a downward trend in MMR from 780 to 510 per 100000 live births corrected for HIVrelated mortality, between 1990 and $2008 .{ }^{17}$ It is possible that HIV-related deaths are also under-reported in sisterhood surveys since respondents may not recall the pregnancy of a relative who died of AIDS (or any other condition not directly related to pregnancy).

Although the very high hospital-based MMR is influenced by a delay in women seeking and accessing the appropriate level of formal healthcare, health workerrelated substandard care at facility level was previously shown to be the most important contributor to poor maternal outcome. ${ }^{18}$ Health worker-related substandard care is compounded by the critical shortage of healthcare personnel and will have to be addressed in order to improve the credibility of formal obstetric services and attract more women to the facility for delivery. Regardless, the facility-based MMR is unacceptably high.

Since the study ended several efforts have been undertaken to improve maternal health in the district. These efforts include: (1) investments in the quality of obstetric care by applying rigorous audit and feedback, (2) increasing access to antiretroviral therapy for those requiring it, including health staff, with district-wide coverage obtained in late 2007, (3) investments in health promotion, infrastructure and training of staff in peripheral sites throughout the district, and (4) the implementation of culturally-sensitive non-monetary incentives to attract women to the facility for delivery alongside the efforts to improve quality. ${ }^{19-22}$ These healthcare-related initiatives to help reduce maternal mortality should be complemented by efforts to empower women and relieve poverty.

Another sisterhood survey in $10-12$ years is indicated to determine whether the initiatives have been successful in reducing maternal mortality. For the moment, the situation looks grim. The threatening failure to achieve MDG 5 should not lead to complacency. Rather, this failure carries with it the moral obligation to intensify the fight against maternal mortality.

Acknowledgements We thank all Ministry of Health and Médecins Sans Frontières staff in Thyolo for their dedication and support during this study. We also thank Ron Wolterbeek for his statistical contribution.

Funding This research received no specific grant from any funding agency in the public, commercial or not-for-profit sectors. 
Competing interests None.

Contributors JB and JvR conceptualised the study. JB initiated it and was responsible for overall collection of data, which were analysed by JB, EL, TvdA and JvR. JB drafted the report that was edited by TvdA and JvR. EL contributed to the statistics. All authors contributed significantly to its intellectual content and have seen and approved the final version of the manuscript.

Provenance and peer review Not commissioned; externally peer reviewed.

\section{REFERENCES}

1. Sachs JD, McArthur JW. The Millennium Project: a plan for meeting the Millennium Development Goals. Lancet 2005;365:347-53.

2. Hill K, Thomas K, AbouZahr C, et al; Maternal Mortality Working Group. Estimates of maternal mortality worldwide between 1990 and 2005: an assessment of available data. Lancet 2007;370:1311-19.

3. Anon. Malawi Demographic and Health Survey, 2004. Calverton, Maryland, USA: National Statistics office Zomba, Malawi, ORC Macro, 2005.

4. Mwagomba B, Zachariah R, Massaquoi M, et al. Mortality reduction associated with HIV/AIDS care and antiretroviral treatment in rural Malawi: evidence from registers, coffin sales and funerals. PLoS One 2010;5:e10452.

5. Zachariah R, Teck R, Buhendwa L, et al. Community support is associated with better antiretroviral treatment outcomes in a resource-limited rural district in Malawi. Trans $R$ Soc Trop Med Hyg 2007;101:79-84.

6. Graham W, Brass W, Snow RW. Estimating maternal mortality: the sisterhood method. Stud Fam Plann 1989;20:125-35.

7. Anon. Sisterhood method for Estimating Maternal Mortality: Guidance notes for potential users. Switzerland: WHO, 1997.

8. Walraven GE, Mkanje RJ, van Roosmalen J, et al. Assessment of maternal mortality in Tanzania. Br J Obstet Gynaecol 1994;101:414-17.

9. Chiphangwi JD, Zamaere TP, Graham WJ, et al. Maternal mortality in the Thyolo District of Southern Malawi. East Afr Med J 1992;69:675-9.
10. Anon. Safe Motherhood: a review, The Safe Motherhood Initiative 1987-2005. Family Care International, Inc, 2007. http://www. familycareintl.org/UserFiles/File/SM\%20A\%20Review_ \%20Full Report FINAL.pdf.

11. Malawi Safe Motherhood Project 2003: Research Abstracts. Operations Research and Participatory Needs and Assessments 1998-2002. Malawi: Project Management Unit, 2003.

12. Malawi National Road Map for Accelerating the Reduction of Materna and Newborn Mortality. Lilongwe, Malawi, 2005. http://www.wcf-uk. org/attachments/article/251/Malawi_Road_Map.pdf).

13. Population and Housing census 1998, Malawi. Malawi: National Statistic Office, 2000

14. Smith JB, Fortney JA, Wong E. Estimates of maternal mortality ratio in two districts of the Brong-Ahafo region, Ghana. Bull World Health Organ 2001;79:400-8.

15. Hogan MC, Foreman KJ, Naghavi M, et al. Maternal mortality for 181 countries, 1980-2008: a systematic analysis of progress towards Millennium Development Goal 5. Lancet 2010;375:1609-23.

16. Palmer D. Tackling Malawi's human resources crisis. Reprod Health Matters 2000;14:27-39.

17. Trends in Maternal Mortality: 1990 to 2008. Estimates Developed by WHO, UNICEF, UNFPA and the World Bank. WHO, UNICEF, UNFPA and the World Bank, 2010. http://whqlibdoc.who.int/ publications/2010/9789241500265_eng.pdf.

18. Kongnyuy EJ, Mlava G, van den Broek N. Facility-based maternal death review in three districts in the central region of Malawi: an analysis of causes and characteristics of maternal deaths. Womens Health Issues 2009;19:14-20.

19. Bemelmans $\mathrm{M}$, van den Akker T, Ford N, et al. Providing universal access to antiretroviral therapy in Thyolo, Malawi through task shifting and decentralization of HIV/AIDS care. Trop Med Int Health 2010;15:1413-20.

20. Bemelmans M, van den Akker T, Pasulani O, et al. Keeping health staff healthy: evaluation of a workplace initiative to reduce morbidity and mortality from HIV/AIDS in Malawi. J Int AIDS Soc 2011;14:1.

21. van den Akker $\mathrm{T}$, Mwagomba $\mathrm{B}$, Irlam $\mathrm{J}$, et al. Using audits to reduce the incidence of uterine rupture in a Malawian district hospital. Int $J$ Gynaecol Obstet 2009;107:289-94.

22. van den Akker T, Radge G, Mateyu A, et al. Can non-monetary incentives increase health facility deliveries?-The experience in Thyolo District, Malawi. International Health 2011;3:66-8. 